\title{
Effectiveness of the Evaluation Committee in a Higher Education Institution of Tocantins
}

\author{
Vinícius I. Oliveira, Aline D. S. de Carvalho, Layala C. da S. Istofel, and Cláudia P. Orquiza e Gentil V. \\ Barbosa
}

\begin{abstract}
The purpose of this research is to analyze the effectiveness of the Evaluation Committee and verify its impact in the years 2016 and 2017, based on the perception of teachers, students and administrative technicians of a Higher Education Institution of Tocantins (IES). A quantitative survey was carried out, with the application of questionnaires with closed questions and multiple choice contemplating the dimensions Mission and Institutional Development Plan; Teaching; Educational Organization and Management; Infrastructure; Communication with Society; Self-assessment; Research; Extension and Culture; Student-care Policies; Staff and Career Policies; Evaluation and Planning. The research revealed that the Institute is seen as regular, in general, because according to the view of the surveyed, the CPA did not achieve effective results during the observed years in comparison to the study done in the years of 2015-2016 that pointed out that IES has good concept to their audiences, different from the results obtained from this study. It was concluded that many improvements need to be made and management should prioritize the evaluation instruments developed.
\end{abstract}

Index Terms - Self-assessment, evaluation committee, higher education institution.

\section{INTRODUCTION}

Higher education in Brazil has evolved over the years, with the creation of mechanisms for evaluating institutions. In this process, they also grow the number of institutions with higher courses, further increasing the need for the evaluation made by the various instruments created by the Ministry of Education (MEC) to assist in this evaluation.

As mentioned by Tenório and Argollo [1], "The results of the evaluation can produce data by IES, constituting references that allow the definition of actions focused on improving the quality of undergraduate courses, by teachers, technicians, leaders and educational authorities". What is perceived is that the evaluation of higher education is not something of the contemporaneousness, but that it is constitutional and comes from the need for the creation of these institutions.

The research was carried out through the application of questionnaires. In this evaluative context was used the formative evaluation that can take the form of practices like written feedback on a task, essay or project; tests and questionnaires and thus help the development of innovative

Manuscript received May 12, 2018; revised July 2, 2018.

The authors are with Federal University of Tocantins, Master of Science and Health Education, Palmas, Brazil (e-mail: viniciusoliveira@itfo.edu.br, alinedeanne@uft.edu.br, orquizaclaudiapereira@gmail.com, gentil@uft.edu.br). programs incorporating quality teaching and learning [2].

The IES chosen for this survey was inaugurated in April 2003 , with the capacity to serve more than 4,000 (four thousand) students, and is a reference in quality teaching in the capital of Tocantins and region [3].

The data obtained through these questionnaires were tabulated and their results analyzed to verify the effectiveness of this commission, that is, if the management of the Institution used the data evaluated in the annual report of the CPA, which carries out an assessment of the IES in all its aspects, going through the courses offered, faculty, administrative technicians and physical structure, to apply improvements in the university.

In order to assess the impacts of the CPA and the importance of the self-assessment made by this committee, the study sought to answer the following research problem: The CPA had relevance in the scope of the institutional evaluation of IES, according to the view of the teachers, administrative technicians and students, in the years 2016 and 2017 ?

In order to answer this questioning and to highlight the relevance of this study in the academic, economic and social field, the present study was justified by the need to verify what improvements the commission evaluated would have brought to the teaching institution of which is part and which possible practices the Institute should adopt to offer quality courses to society.

The research aimed to analyze the impacts and relevance and opinion of the teachers, students and administrative technicians on the form of the performance of the CPA and effectiveness. A comparative study was made between the data obtained from the survey and the CPA report of the year 2015-2016.

Any and all research to be completed requires theoretical background. Thus, in the course of this study will be presented several concepts, according to the vision of renowned authors in the area, being these essential for the accomplishment of said study and for the effectiveness of the research.

Among the concepts shown are the CONAES [4], responsible for supervising and coordinating the processes of institutional evaluation, SINAES [5], responsible for evaluating the institution as a whole, using auxiliary instruments. One of these instruments, object of this study is the CPA, responsible for conducting the Institution's self-evaluation, and subsequently bringing the results of this evaluation to the higher levels of the university [6].

In this specific case, the CPA analyzed will be that of the IES of the state of Tocantins, established in accordance with 
the requirements of the MEC, which has an internal regiment, elaborated according to the specificities of the Institution [7].

After showing the concepts that guided the study, the the next session are the methodological procedures used. The research carried out is descriptive exploratory, which brings the author's first contact with the problem and in which he describes his characteristics. An exploratory research is one based on studies that seek to discover ideas, seek to acquire greater familiarity with the subject researched and may not formulate a hypothesis. These are researches that seek to create new hypotheses and carry out new, more structured researches [8].

The instruments for data collection were composed of questionnaires, with closed questions, applied through a web tool, with the administrative and teaching technicians and also printed, as well as those applied with the students.

For the analysis of the data was applied the descriptive statistic, through the elaboration of graphs to demonstrate the results of the research performed. Finally, we find the considerations of the work developed and how it can contribute to future works of the same theme.

\section{RESEARCH MethodOlOGY}

For this research, the methodological procedures sought to verify the effectiveness of the Evaluation Commission of the IES of Tocantins on the point of view of its publics, among which are the teachers, students and administrative technicians, through application of questionnaires that had the objective to verify what the CPA has achieved from improvements to the Istitution as a whole. The study also sought to make a a comparison between the data obtained from the survey conducted by the CPA in the year 2015-2016, in which these three segments were heard, to assist in verifying the effectiveness of that commission.

For the conclusion of the research, questionnaires were applied with the three segments involved, in which the population was chosen by simple random sampling, which according to Rabelo [9], this type of sampling is the most used, due to its accuracy and be able to perform an effective sampling, besides the facility to be applied, making all the elements of the population researched have the same probability of being part of the sample.

In the study in question the total population was 207 teachers, 107 technicians and 1,437 students. Where they were selected a percentage of $23 \%$ (twenty-three percent) of teachers, $23 \%$ (twenty-three percent) of students and 26\% (twenty-six percent) of technicians. Due to the difficulty in applying the questionnaires, the percentages reached were not the same for the three publics used in the sample, which did not compromise the research, where each parcel was effectively represented.

The type of research used was descriptive exploratory research. Regarding exploratory research, according to William Costa Rodrigues [10], "its objective is the initial characterization of the problem, its classification and its definition. It is the first stage of all scientific research". With this, the exploratory research seeks to lead the author to have the first contact with the problem that will be analyzed, so that he can familiarize himself with this theme and thus study it more objectively.

The purpose of this study was to verify the impact of this committee on academic management in the years 2016 and 2017 , that is, if it had any effect on the Institution, through the analysis of the data obtained with the questionnaires applied.

Descriptive research, as Kauark, Manhães and Medeiros [11] argue, "aims to describe the characteristics of a particular population or phenomenon, or the establishment of relationships between variables. It involves the use of standardized data collection techniques: questionnaire and systematic observation". Among the objectives of the descriptive research, it stands out the fact that it raises the viewpoint of the segments to be surveyed in relation to the object of the analysis. In this case the study allowed to verify, through the opinion of the students, teachers and technicians of the IES the impacts of the self-assessment developed by the commission.

In view of the research model adopted, aiming at the achievement of the proposed objectives and considering that the study is quantitative, the instrument used for data collection was composed of questionnaires, applied with each segment researched. According to Castilho, Borges and Pereira [12], a questionnaire "is a technique of collecting data through an ordered series of questions, which must be answered in writing, without the presence of the interviewer". The questionnaires can be elaborated with open or closed questions, depending on the type of research that is to be carried out. The study in question worked with closed questions, addressed to the public involved, which included the following dimensions: Mission and Institutional Development Plan; Teaching; Educational Organization and Management; Infrastructure; Communication with the Society; Self-assessment; Research; Extension and Culture; Student-care Policies; Staff and Career Policies; Evaluation and Planning.

The questions asked were specific to each plot surveyed, noting that they had common questions between both questionnaires applied, where they tried to obtain real answers on how each public surveyed evaluates the IES on all its aspects, within the dimensions that were observed.

As previously explained, in order to facilitate the investigation about the topic, the Google Docs tool was also used as an auxiliary instrument to answer the questionnaires. These were applied with the administrative technicians, seeking agility in the conclusion of the study carried out During the research conducted with the teachers were applied, in addition to those made available on the platform, printed questionnaires.

These two models of application of the questionnaires were elaborated aiming at facilitating the application and tabulation of the data of the mentioned questionnaires, since it brought more agility and efficiency, since not always there is availability of both the researcher and those researched for effective study.

For the data analysis, descriptive statistics were used through the distribution of percentages and mean. As stated by Guedes [13], descriptive statistics, whose basic objective is to synthesize a series of values of the same nature, thus allowing an overall view of the variation of these values, organizes and describes the data in three ways: by means of 
tables, graphs and descriptive measures.

With this, the data were exposed through the elaboration of graphs, as will be shown at the end of the study, which made possible a better understanding of the presented results.

As the study carried out involves the Institution as a whole, some obstacles appeared during the research. One of them was the difficulty in obtaining the participation of these segments. With the questionnaires now applied with teachers and administrative technicians, those through the Google Docs platform, the greatest difficulty perceived was the lack of availability of the same to respond, since due to their daily assignments this has become a complicator. What facilitated the study with the teachers was the application, also, in person, in which the respondents who could not respond via the platform, the researcher applied simultaneously to the questionnaires with students, in the classroom, seeking to streamline and facilitate the process. These two forms of research were still necessary due to the fact that the research had a predetermined period to be carried out, aiming not to disturb the study in question.

Even in the face of the difficulties that arose during the study, it was sought to perform it in the most efficient way possible, since one of the main objectives of the study was to verify if the results obtained through the self-assessment by the commission were actually applied by the management of the Institution and how these results were being seen by its publics, the main beneficiaries of the CPA's impact on the Institution.

\section{ANALYSIS AND DISCUSSION OF RESULTS}

To reach the desired results, as mentioned later, the research consisted of the application of questionnaires with the three segments of the Institute: teachers, administrative technicians and students. These questionnaires consisted of objective and closed questions, of multiple choice, with specific questions for each public searched, where the number of questions varied according to each segment involved.

The research instruments were applied in two ways: with the students through field research, in which the questionnaires were applied in the classroom, with the proper authorization of the teachers. These consisted of ten (10) objective questions. Already with the teachers, made available in Google Docs as well as applied in the classroom, concomitant with the application with the students. Already with the administrative technicians were only available via Google platform, answered according to the availability of these audiences, as it was the most feasible way to reach a quantitative close to the ideal. Twelve questions were addressed to the teachers and 11 (eleven) questions for the technicians, both of whom also had objective questions.

As the main objective of the research was to verify the effectiveness of the CPA of the IES of Tocantins, the data extracted from the application of the questionnaires were analyzed and subsequently compared with the CPA report of the year 2015-2016, so that it could be verified if such the commission has achieved some improvement in subsequent years, i.e. in the years 2016 and 2017. It was also sought to answer the following questions: What is the relevance of the information obtained from the evaluations carried out by the IES CPA? And what are the impacts of CPA assessments on academic management?

The results were grouped according to the dimensions analyzed and also according to the questions asked, because there were common questions addressed to all during the study, as well as questions directed to a certain segment.

The percentage obtained from the study with each of these segments and the subsequent analysis of these data will be presented below. The quantitative data analyzed were those that were available during the research period, provided by the Coordination of Cadastre and Educational Research.

TABLE I: QUANTITATIVE OF RESEARCHED TEACHERS

\begin{tabular}{|l|l|l|}
\hline Total teachers & $\begin{array}{l}\text { Number of teachers } \\
\text { interviewed }\end{array}$ & Percentage (\%) \\
\hline 207 & 48 & 23 \\
\hline
\end{tabular}

TABLE II: QUANTITATIVE OF RESEARCH ADMINISTRATIVE TECHNICIANS

\begin{tabular}{|c|c|c|}
\hline $\begin{array}{l}\text { Total } \\
\text { Administrative } \\
\text { Technicians }\end{array}$ & $\begin{array}{l}\text { Number of } \\
\text { administrative } \\
\text { technicians interviewed }\end{array}$ & Percentage (\%) \\
\hline 107 & 28 & 26 \\
\hline
\end{tabular}

TABLE III: QUANTITATIVE OF STUDENTS INVESTIGATED

\begin{tabular}{|l|l|l|}
\hline Total of Students & $\begin{array}{l}\text { Number of students } \\
\text { interviewed }\end{array}$ & Percentage $(\%)$ \\
\hline 1437 & 336 & 23 \\
\hline
\end{tabular}

Based on the analysis of the questionnaires and the tabulation of the data obtained with the research, the analysis of the results achieved and the percentages reached in each question follows.

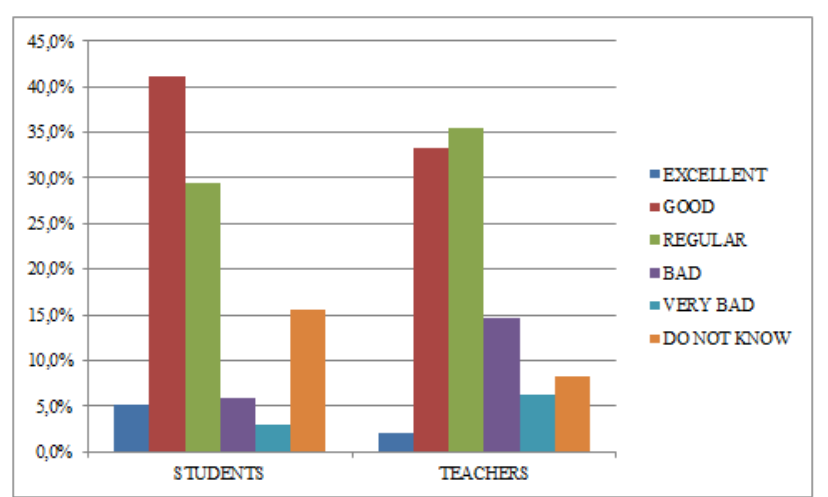

Fig. 1. How do you evaluate the accomplishment of the mission and the Institutional Development Plan (PDI) of IES?

According to Fig. 1, of the total number of students interviewed, in relation to the fulfillment of the mission and PDI, $5.1 \%$ considered excellent, while of the total of teachers only $2.1 \%$, and $41.1 \%$ of the students answered that the Institution fulfills a good form and $33.3 \%$ of teachers, $29.5 \%$ of students report as regular and of teachers this number is $35.4 \%$, as bad only $6 \%$ of students and teachers $14.6 \%$. A little more than $3 \%$ of the students think very bad and about the teachers $6.3 \%$ and finally $15.5 \%$ of the students did not know how to respond to $8.3 \%$ of the teachers.

Taking into account these results and comparing them with the CPA report for the year 2015-2016, it was verified that the 
Institute fulfills satisfactorily with its mission and PDI, according to the majority of those surveyed. However, it should be pointed out that a large percentage of these publics evaluated the fulfillment of this dimension as regular, while many did not know how to respond due to the lack of knowledge about this dimension, as well as highlighted in this same comparative report.

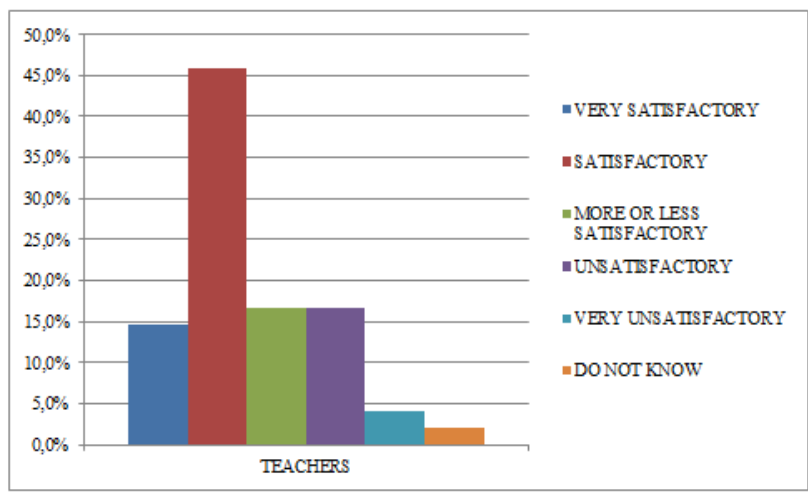

Fig. 2. How do you rate the number of teachers in relation to the IES students?

The teachers of Fig. 2, when questioned about the quantity of professors in relation to the students of IES, $14.6 \%$ find it very satisfactory, $45.8 \%$ consider it satisfactory, $16.7 \%$ think it is more or less satisfactory, this same percentage sees it as unsatisfactory and yet little more than $2 \%$ answered not knowing.

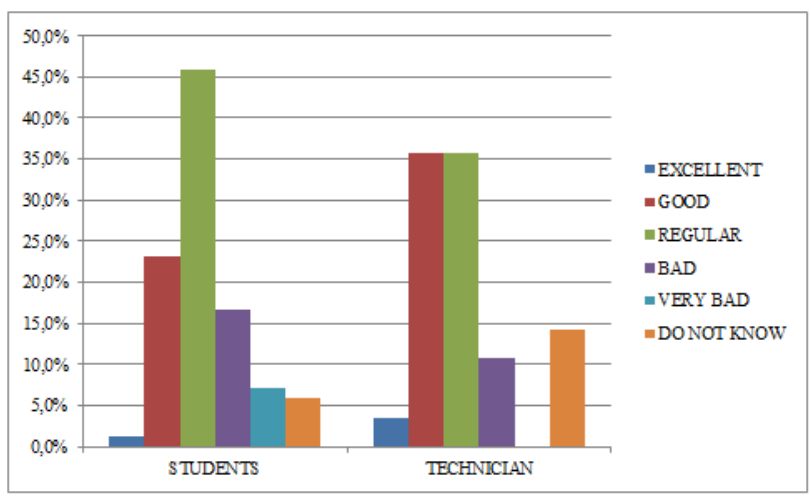

Fig. 3. How do you assess the relationship between IES students and technicians?

Questioned about the relationship between students and technicians, Fig. 3 considers, respectively: $1.2 \%$ of students find it excellent, compared to $3.6 \%$ of technicians, $23.2 \%$ of students analyzed as good, while the technicians were $35.7 \%$, $45.8 \%$ of students and $35.7 \%$ of technicians consider regular, $16.7 \%$ of students said to be poor, to $10.7 \%$ of technicians. As a very bad thing only the students were heard, totaling $7.1 \%$ of the interviewees and finally $6 \%$ of these students and $14.3 \%$ of the technicians answered not knowing.

According to the compared CPA, the students and technicians evaluated how to regulate this dimension in aspects related to their courses.

Examining the Teaching dimension of Fig. 4, which was analyzed only from the point of view of the students, it was verified that of these, $17 \%$ consider excellent, $63.7 \%$ see as good, $17.3 \%$ indicate as regular, $1.2 \%$ think it's bad, and less than $1 \%$ think it's very bad. No one interviewed checked the option I do not know. Given these data, it is observed that according to most of the students, the Institution fulfills in a satisfactory way with the quality of the offered education. In the CPA report, education was also considered good.

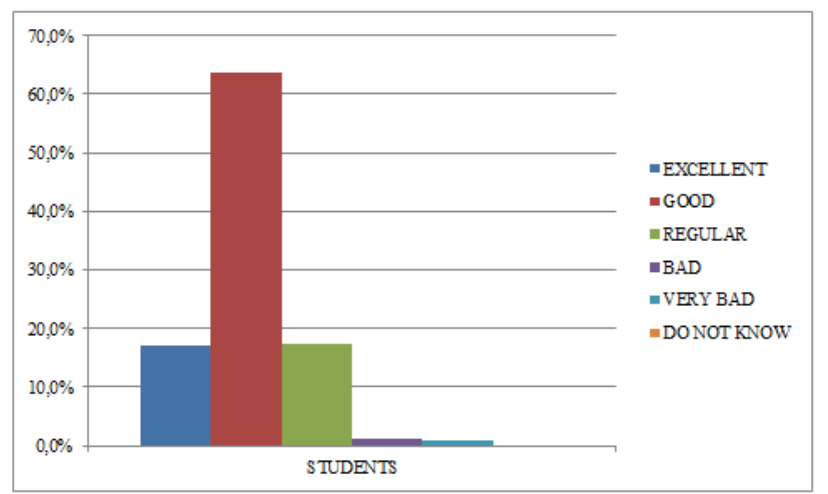

Fig. 4. How do you evaluate the teaching offered by IES?

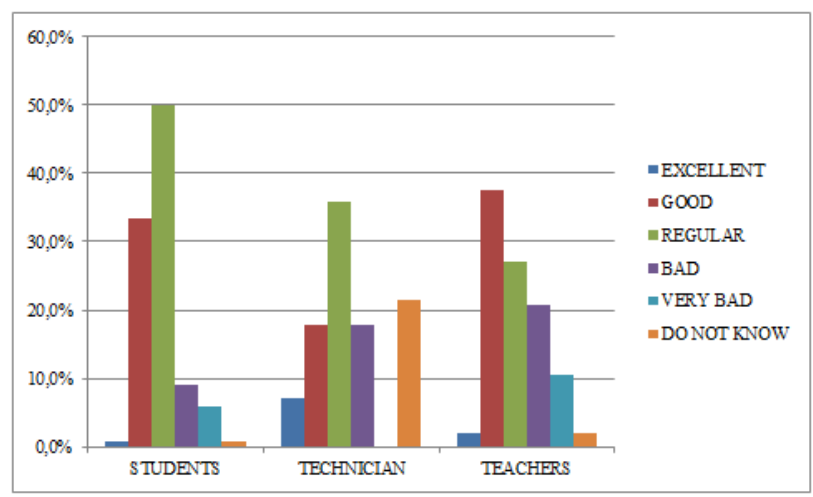

Fig. 5. How do you generally assess attendance in the IES sectors?

Evaluating the attendance in general, in the sectors of IES, which fits in the dimension Management and Educational Organization, Fig. 5 shows, from the point of view of the students, that less than $1 \%$ consider it excellent, $33.3 \%$ evaluate as good, already $50 \%$ consider regular, $8.9 \%$ said to think it's bad, $6 \%$ see as very bad and less than $1 \%$ opined not to know. It can be verified that half find regular the service offered by the Institution.

Following the dimension of the above dimension, technicians questioned how to evaluate the dimension itself, $7.1 \%$ said to be excellent, $17.9 \%$ considered as good, $35.7 \%$ considered regular, $17.9 \%$ said to be bad and $21.4 \%$ did not know how to respond. $2.1 \%$ of the teachers considered it excellent, when $37.5 \%$ rated it as good, $27.1 \%$ said they were regular, $20.8 \%$ considered bad, $10.4 \%$ were very poor and only $2 \%$ did not know how to respond.

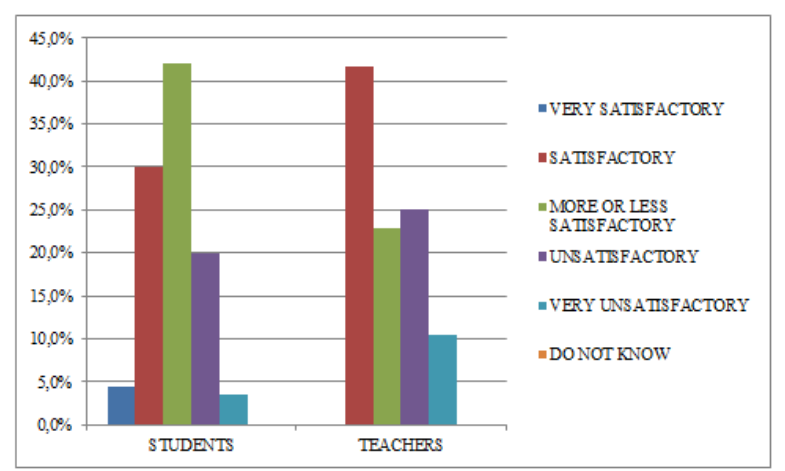

Fig. 6. On the physical infrastructure, how do you see the IES facilities?

In the Physical Infrastructure dimension, Fig. 6, 4.5\% of 
the students said they considered it very satisfactory and none of the teachers responded to this alternative; $30.1 \%$ of the students and $41.7 \%$ of the teachers evaluated as satisfactory; $42 \%$ of the students and $23 \%$ of the teachers chose as more or less satisfactory; $20 \%$ of students and $25 \%$ of teachers as unsatisfactory and $3.6 \%$ of students and $10.4 \%$ of teachers say very unsatisfactory; finally, both publics surveyed answered the option I do not know.

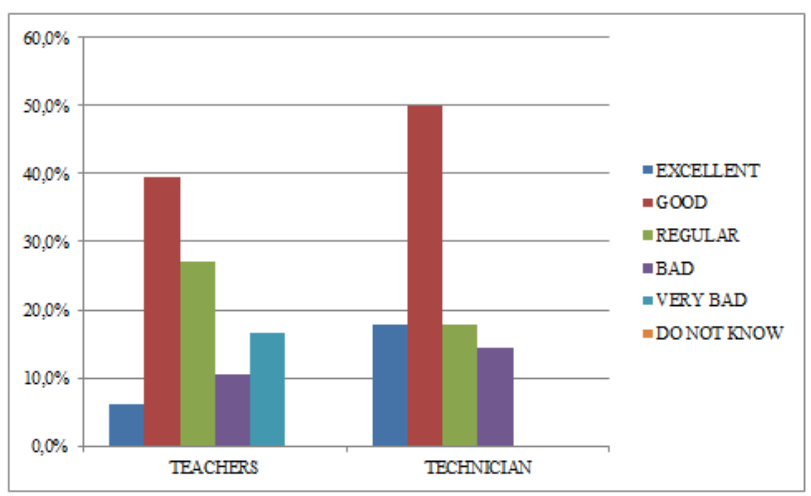

Fig. 7. With regard to physical space in the work environment, how do you rate it?

According to Fig. 7, technicians and teachers were asked about how they evaluate the physical space in their work environment, $17.9 \%$ of technicians and $6.3 \%$ of teachers find it excellent, already $50 \%$ of technicians for $39.6 \%$ of teachers consider it good, $17.9 \%$ of technicians versus $27.1 \%$ of teachers analyze how regular, $14.3 \%$ of the technicians compared to $10.4 \%$ of teachers said to be poor. Only the teachers scored the very bad alternative, which $16.7 \%$ answered. The last option, I do not know, was not answered by any of the respondents.

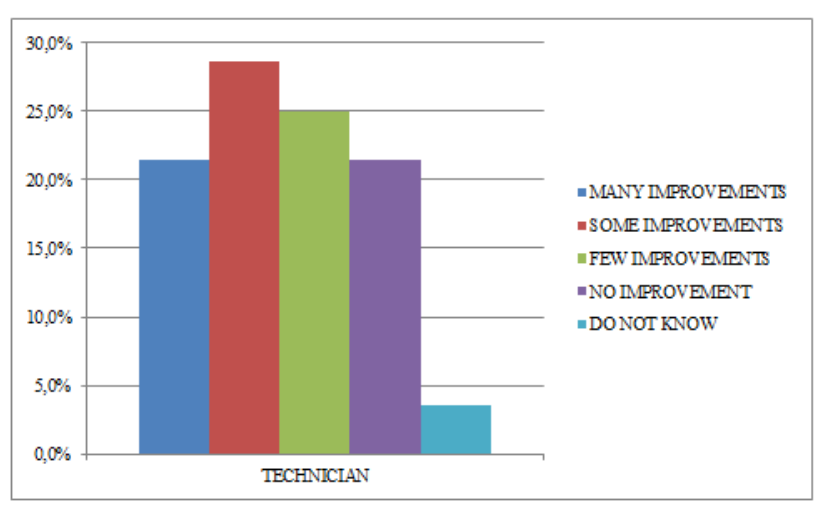

Fig. 8. Improvements in infrastructure of the sector compared to previous years.

Still on the infrastructure of the sector in which they are crowded, Fig. 8 shows that the technicians were questioned about the improvements made in relation to previous years. Of these, $21.4 \%$ said that many improvements were made, $28.6 \%$ said that there had been some improvements, $25 \%$ saw that few improvements were made, $21.4 \%$ felt that no improvement had been made and $3.6 \%$ responded to I do not know.

According to the respondents' answers, the physical facilities of the IES are satisfactory, specifically for teachers and technicians. These evaluate your workspace as good. Already when the improvements made by the work sector, answered only by the technicians, opinions are divided, where much says many improvements have been made. Next to the same quantitative considers that there were only some improvements and still with a similar percentage the respondents said that no improvement had occurred.

Checking the CPA data, teachers approve the expansion of the physical space of the IES, the students have already said that the space of the new library is satisfactory and the technicians are satisfied with their work environment, however it needs spaces common to all, material assistance for the better development of their work. The report also showed that students believe that there should be improvements in the structure of classrooms.

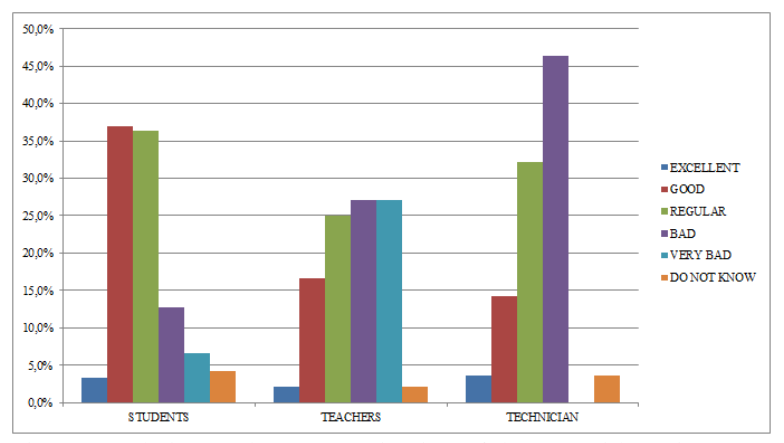

Fig. 9. In relation to the communication of the IES with society, you consider.

With regard to the Communication dimension with the Society, with questionnaires answered by technicians, Fig. 9 reports that $3.6 \%$ of the technicians, $3.3 \%$ of the students, and $2.1 \%$ of the teachers consider it excellent, $14.3 \%$ of the technicians, $37 \%$ of the students and still $16.7 \%$ of the teachers analyze how good. $32.1 \%$ of the technicians, $36.3 \%$ of the students and $25 \%$ of the teachers evaluated as regular, as bad $46.4 \%$ of the technicians, $12.8 \%$ of the students and $27.1 \%$ of the teachers. For the technicians, the option was not very bad, but of the students $6.5 \%$ and the teachers $27.1 \%$ find this communication very bad. And finally $3.6 \%$ of technicians, $4.2 \%$ of students and slightly more than $2 \%$ of teachers marked the option I do not know.

Confronting with the CPA data, internally teachers and students consider communication with society as good. Already the technicians said that the institute is well seen by the outside society, which they consider as a positive point. At the same time, however, they feel that communication with this external public is fragile and needs to be strengthened.

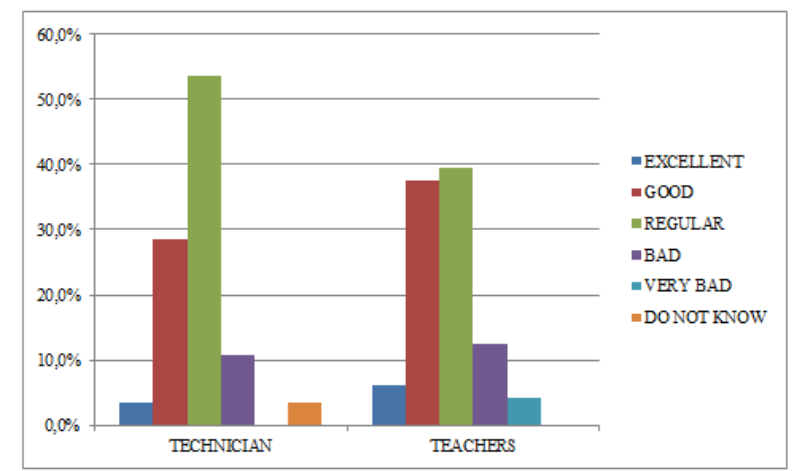

Fig. 10. How do you evaluate the relationship between technicians and teachers?

Fig. 10 reports in the Self-Assessment dimension, where administrative and teaching staff were interviewed. When 
questioned about the relationship between the two, $3.6 \%$ of the administrative staff and $6.3 \%$ of the teachers said they were excellent, $28.6 \%$ of the technicians to $37.5 \%$ of teachers feel good, yet $53.6 \%$ of technicians versus $39.6 \%$ of teachers see it as regular, $10.7 \%$ of technicians and $12.5 \%$ of teachers consider it bad. Only the teachers scored the bad option, with $4.2 \%$ responding to this option, and still, $3.6 \%$ of the technicians indicated they did not know, while no percentage of teachers marked this question. Most respondents in the research consider regulating the relationship between technicians and teachers.

During the CPA survey, the technicians said the relationship was good in their work environments.

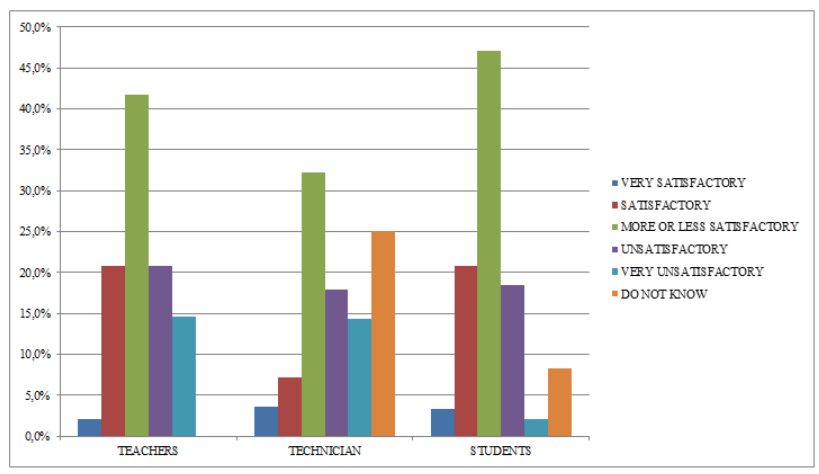

Fig. 11. How do you evaluate investments for teaching, research, postgraduate and extension of IES?

With regard to investments in education, research, postgraduate and extension, Fig. 11 shows that $2.1 \%$ of teachers, $3.6 \%$ of technicians and $3.3 \%$ of students find it very satisfactory, while $20.8 \%$ of the students, $7.1 \%$ of the administrative technicians and $20.8 \%$ of the Students consider only satisfactory, $41.7 \%$ of teachers, $32.1 \%$ of technicians and $47 \%$ of students consider more or less satisfactory, $20.8 \%$ of the teachers, $17.9 \%$ of the technicians and $18.5 \%$ of the students evaluated as unsatisfactory; $14.6 \%$ of the teachers, $14.3 \%$ of the technicians and $2.1 \%$ of the students said they were very unsatisfactory. Teachers said they did not know, while $25 \%$ of the technicians and $8.3 \%$ of the students marked this option. In the great majority, the respondents said that the investments in this area were more or less satisfactory and yet another considerable portion responded that they were unsatisfactory.

Contrary to the commission's data, teachers consider research policies as regular and the link between research and other academic activities as bad. The students, however, have seen investment in research as good, but they believe that there should be greater democratization of access to scientific initiation fellowships.

According to Fig. 12, the dimension of Student Service Policies, only from the point of view of the students, when questioned about these assistance policies, such as scholarships offered for teaching aid, says that $12.8 \%$ said they found much satisfactory, $45.5 \%$ said they were satisfactory, while $31.5 \%$ said that these policies are more or less satisfactory, $6.3 \%$ consider them unsatisfactory, $1.5 \%$ see them as very unsatisfactory and, finally, $2.7 \%$ answered no to know. It was noticed that most of the students consider the scholarships offered by the IES to be satisfactory, being this a strong point of the Institution. Observing the commission's report, the students sought the need for improvements in meeting these policies.

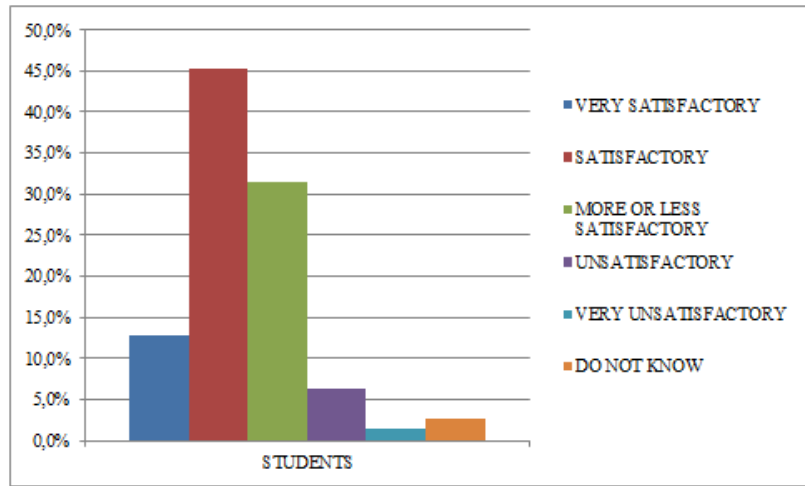

Fig. 12. With regard to student service policies, how do you rate?

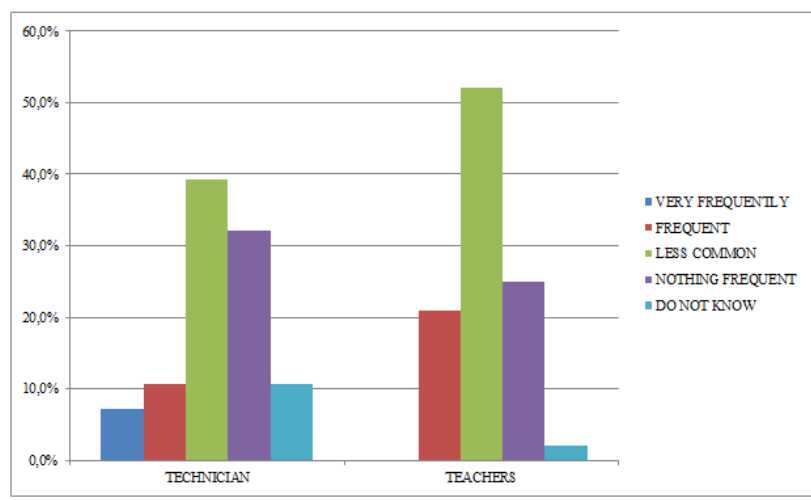

Fig. 13. In relation to the qualification and updating courses offered by IES, how do you rate this offer?

With questions asked of technicians and teachers, when questioned about the qualification and update courses offered by the institute, $7.1 \%$ of the technicians said they were very frequent in Fig. 13, which deals with Personnel and Career Policies. Of the teachers, none has marked this option. At present, $10.7 \%$ of the technicians and $20.8 \%$ of the teachers find it frequent, $39.3 \%$ of the technicians and $52.1 \%$ of the teachers consider it as less common, $32.1 \%$ of the technicians and $25 \%$ last $10.7 \%$ of the technicians and $2.1 \%$ of the teachers answered not knowing. According to most, the courses offered are infrequent.

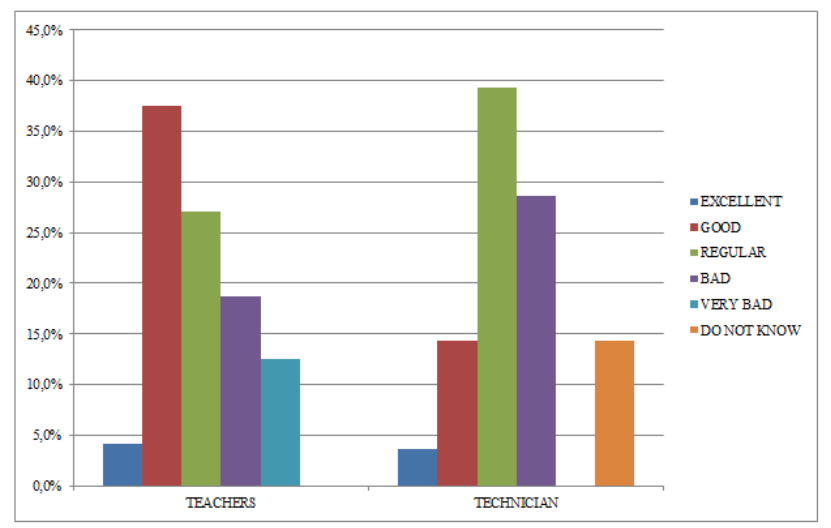

Fig. 14. How do you evaluate server recovery policies?

In this context of public policies for education, governmental initiatives are observed in the establishment of goals and actions that provide the development of the citizen, providing, in the 1988 Constitution, the Law of Guidelines and Bases/1996, in the National Education Plan (PNE)/2001 
and in the Education Development Plan (PDE)/2007, guidelines for the expansion and improvement of the quality of education [14].

During the commission's research, teachers responded that qualification programs demand improvements by considering them as regular.

In Fig. 14 teachers and technicians were asked how they evaluate the valorization policies, where $4.2 \%$ of teachers and $3.6 \%$ of technicians consider it excellent, $37.5 \%$ of teachers and $14.3 \%$ of technicians see as good , $27.1 \%$ of teachers as well as $39.3 \%$ of technicians find it regular, $18.8 \%$ of teachers to $28.6 \%$ of technicians said to be bad. Only teachers had the very bad option to respond, where $12.5 \%$ marked this alternative and therefore none of the teachers interviewed opted for the option I do not know, while $14.3 \%$ of the technicians considered it. Most of the teachers consider the valorization policies as good, while the technicians already see them as regulars.

According to the commission's calculations, half of the teachers consider the criteria for career progression to be good. The technicians understand that the effective for attending students should be expanded and at the same time they are satisfied with their work environment.

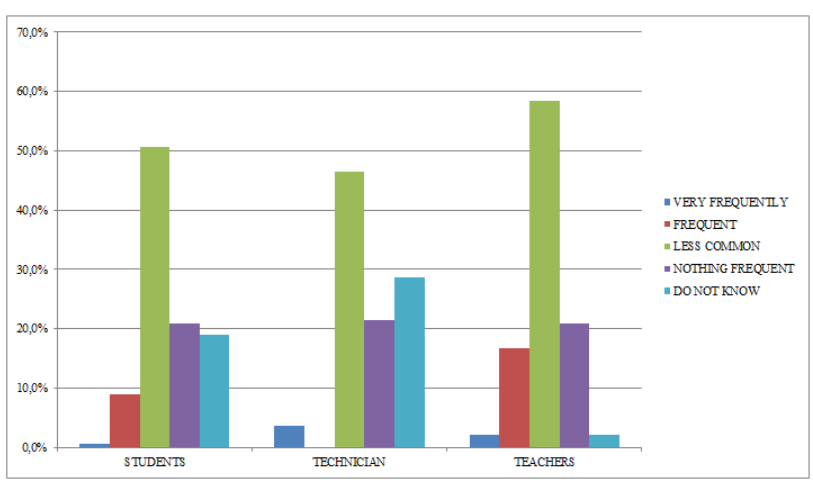

Fig. 15. How do you evaluate participation in evaluation and planning meetings?

In Fig. 15, which deals with Evaluation and Planning, the three segments involved in the survey, when questioned about their participation in evaluation and planning meetings, $0.6 \%$ of the students, $3.6 \%$ of the technicians and $2.1 \%$ of teachers were very frequent, $8.9 \%$ of the students and $16.7 \%$ of the technicians stated they were frequent. Of the teachers, none spoke on the subject. Considering uncommon, $50.6 \%$ of the students, $46.4 \%$ of the technicians and $58.3 \%$ of the teachers answered this alternative. Alredy $20.8 \%$ of the students, $21.4 \%$ of the technicians and $20.8 \%$ of the teachers were not very frequent. Finally, $15 \%$ of the students, $28.6 \%$ of the technicians and $2.1 \%$ of the teachers answered not knowing the this questioning. The majority of those interviewed consider that participation in these meetings is infrequent.

According to the CPA, most of the teachers point out how excellent or good they have attended the course planning meetings, while the technicians saw how good they are in planning their work sectors. The report also highlights the significant number of teachers who chose how to regulate their contribution to the evaluation of the entity.

The research is valid and extremely important in order to list answers to problems, to point out the weaknesses of the Evaluation Committee itself, and to serve as a subsidy for decision making by the active manager with the intention of guiding improvements in teaching, in relation interpersonal and organizational management, through planning aimed at excellence in education.

\section{FinAl CONSIDERATIONS}

The present study sought to verify the impacts of the Evaluation Commission of the IES of the State of Tocantins in the years 2016 and 2017, according to the view of teachers, administrative technicians and students. An IES is a social institution of an essentially pedagogical nature, and to understand it in this way helps to better understand the "institutional" dimension of evaluation [15].

A comparative study was carried out between the CPA report for the year 2015-2016 and the data obtained from the application of questionnaires, with questions directed to each of the three segments surveyed. In this way it was possible to analyze the relevance of the evaluations made by this committee in the academic field, that is, if the managers used it to make improvements in the IES of the State of Tocantins.

The study also made it possible to gather information that will help other researchers in future work related to the subject, as well as future professionals who will enter higher education, since it will serve as a basis to verify how the university, object of the study, is seen before the community.

The analysis verified the impacts of the CPA and if it was being used as a tool for the management of the Institution to effect improvements, because as Gadotti says, "the institutional evaluation has the scope to rethink the institution, aiming at improving the quality of the services it provides the beneficiary population and the strengthening of their social commitment (in the case of educational institutions). It is a process of self-criticism involving all segments of the institution" [16].

It was also studied the importance of the evaluations made by this committee within the IES of the state of Tocantins, if it has had any positive effect in the University. All of these objectives were aimed at answering the following research problems: What is the relevance of the information obtained from the evaluations carried out by the CPA in the IES? What are the impacts of CPA assessments on academic management?

With the study it was verified the need for many improvements to be made in the structural and academic part of the IES of the state of Tocantins. According to the results obtained, the Institute was evaluated as regular by its publics. On the other hand, the CPA report for the year 2015-2016 pointed out that the IES acquired the good concept in a large part of the results, so the comparative analysis of the years showed a different reality today, even showing regression in some aspects.

The report of the Ministry of Education (MEC) confirms the above notes. An evaluation was done by the same, using several factors, including the CPA to measure the Institutional Concept (CI), which in this case obtained a grade of 3 (three), on a scale of up to 5 , considering the highest value as the best grade [17] .

Despite the discrepancies between the results of the report and the research carried out, some changes have been carried 
out in the institution, such as the expansion of IES, divisions in some sectors, aiming at optimizing the work of professionals and attending to the students.

In view of the presented scenario, it is verified that the IES still has much work ahead to reach a level of excellence. As a contribution of this article, managers are advised to work in an integrated way, with all the publics involved in the context of the IES, to prepare an action plan based on the diagnoses raised by the latest CPA research, focusing on in achieving the institutional objectives. The greater the engagement of the public involved in the research, the better the quality of the information collected. The results will be much closer to reality. An accurate diagnosis will give managers a holistic view and, therefore, more assertiveness and effectiveness in decision making with a focus on excellence management.

For future work related to the topic, the proposal is to improve the evaluation made by the CPA, because the questions are cast and most of them make it difficult for the respondents to understand half of the dimensions they are evaluating, which adds More knowledge of what these dimensions would be and how they impact the Institution as a whole. With these adaptations the academic community would have more real information about the Institution, contributing in the choice of its future university and enabling to the managers the improvement of the courses offered and of the Institution as a whole.

\section{REFERENCES}

[1] R. M. Tenório and R. S. Argollo, "SINAES from the perspective of CPA members: Implementation, conduction and evaluation," EDUFBA, pp. 103-122, 2009.

[2] F. M. Araújo, Formative Evaluation and its impact on improving learning," PhD dissertation, University of Lisbon, Faculty of Human Motricity, Lisbon, 2015.

[3] D. Ti. (2016). Federal Institute of Tocantins. Secretariat of Professional and Technological Education. [Online]. Available: http://portal.ifto.edu.br/palmas/acesso-a-informacao-palmas/institucio nal

[4] Brazil. (2004). Law no. 10,861. Establishes the National System for the Evaluation of Higher Education - SINAES and Other Measures, Civil House, Brasilia. [Online]. Available: http://www.planalto.gov.br/ccivil_03/_ato2004-2006/2004/lei/110.86 1.htm

[5] (2014). Ordinance No. 2,051. Regulates the Procedures for Evaluation of the National System of Evaluation of Higher Education SINAES and other measures. Official Journal of the Union, Brasilia. [Online]. http://portal.mec.gov.br/arquivos/pdf/PORTARIA_2051.pdf

[6] (2013). Resolution no. 71/2013/CONSUP/IFTO, of December 11, 2013. The Internal Rules of the Evaluation Committee. [Online] Available:

http://www.ifto.edu.br/ifto/colegiados/consup/documentos-aprovados /regimentos/cpa/regimento-cpa-ifto.pdf/view

[7] (2017). Decree $n^{\circ}$ 9.235, of December 15, 2017. Plateau. Brasilia. [Online]. Available: http://www.planalto.gov.br/ccivil_03/_ato2015-2018/2017/decreto/D 9235.htm

[8] M. F. Oliveira, "Scientific methodology: A manual for conducting research in Administration," UFG, vol. 72, 2011.

[9] R. Rabelo, (2014). Sampling. Ebah - Social Network of Academic Sharing. [Online]. Available: http://www.ebah.com.br/content/ABAAABNXgAD/amostragem

[10] W. C. Rodrigues, (2007). Scientific Methodology. UNEMAT - State University of Mato Grosso. [Online]. Available: http://sinop.unemat.br/site antigo/prof/foto_p_downloads/fot_8672a ula_04_-_william_costa_-_metodologia_cientyfica_pdf.pdf

[11] F. D. Kauark, F. C. Manhães, and C. H. Medeiros, Research Methodology: A Practical Guide, Itabuna: Via Literarum, 2010.

[12] A. P. Castilho, N. R. Borges, and V. T. Pereira, Scientific Methodology Handbook, vol. 82, 2011.

[13] T. A. Guedes et al., Descriptive Statistics, vol. 49, 2005.

[14] C. Z. Reis, S. D. Silveira, and M. A. Ferreira, "Self evaluation in a federal higher education institution: results and implications," Avaliação (Campinas), vol. 15, no. 3, pp. 109-129, 2010.

[15] J. D. Sobrinho, "University: Socialization processes and pedagogical processes," Cortez, vol. 15, 1995.

[16] M. Gadotti, "Institutional evaluation: Necessity and conditions for its realization," Paulo Freire Institute, 2010.

[17] BRAZIL. (2017). Ministry of Education. [Online]. Available: http://emec.mec.gov.br/emec/consulta-cadastro/detalhes-ies/d96957f4 $55 \mathrm{f} 6405 \mathrm{~d} 14 \mathrm{c} 6542552 \mathrm{~b} 0 \mathrm{f} 6 \mathrm{eb} / \mathrm{NDc} 4 \mathrm{Ng}==$

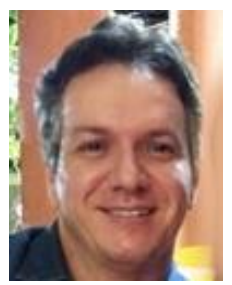

Vinícius I. Oliveira was born in Goiânia, Goiás, on December 9, 1977. He studied in systems analyst at the University of Tocantins - UNITINS in 1999. He specialied in public management and the Teaching of Higher Education by Instituto Tocantinense de Pós-Graduação - ITOP in 2006. He works as a titular professor of the Federal Institute of Education, Science and Technology of the Tocantins - Palmas.

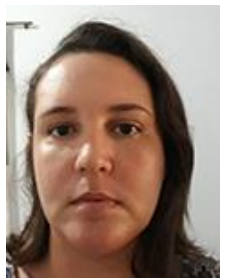

Aline D. S. de Carvalho was born in Imperatriz - MA in 1988. She is biologist at the Federal University of Tocantins in 2010. She is specialied in environmental education and management since 2014. She worked as administrative technician in education at the Federal University of Tocantins, Palmas.

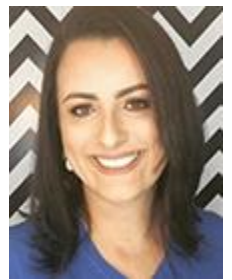

Layala C. da S. Istofel was born in Paraíso do Tocantins, Tocantins, on September 17, 1980. She was graduated in social communication - journalism by the University of Tocantins Foundation (Unitins) in 2002 She is specialied in management in organizations by the Brazilian Institute of Postgraduate and Extension (IBPEX). She is also specialied in communication and marketing from the Catholic University of Tocantins (FACTO); and in teaching communication / journalism: Contemporary issues at Federal University of Tocantins (UFT). She works as an analyst in communication for Sebrae Tocantins.

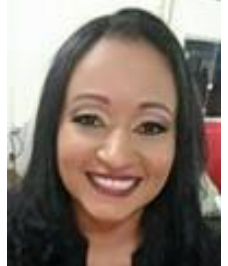

Cláudia P. Orquiza was born in Grajaú, Maranhão, Brazil, on June 10, 1986. He is currently an administrative assistant in the syndicate representing the workers of Sistema $\mathrm{S}$ and non-profit entities (SENALBA/TO), with state territorial coverage. She has experience in the administrative area.

She holds a technical course in secretarial and is a graduate of the superior course of technology in public management, both by the Federal Institute of Tocantins.

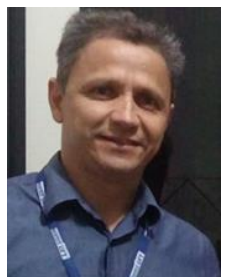

Gentil V. Barbosa got the doctor degree by the Federal University of Rio de Janeiro. Currently he is adjunt II teacher by the Foundation of the Federal University of Tocantins and the masters program in teaching science and health. He has experience in the area of computer science with emphasis in teleinformatics, acting primarily in the following: administration and management of networks, complex networks and analysis and modeling of computational systems. 